\title{
Is dojo the spiritual place in aikido?
}

\author{
Zdenko REGULI*, Michal VIT, \& Jitka ČIHOUNKOVA \\ Faculty of Sport Studies - Masaryk University, Brno (Czech Republic) \\ International Martial Arts and Combat Sports Scientific Society - IMACSSS (Poland)
}

5th IMACSSS World Scientific Congress Abstracts, Rio Maior (Portugal), October 6-8

Section: Historical, sociological and philosophical issues of MA\&CS

Type: Oral communication

\section{Introduction}

Fighting culture as a part of the civilization is institutionalized in martial arts. Some parts of the world preserved martial arts not only as combat systems, but also as part of movement, historical, spiritual, religious culture (Green, 2001). Aikido as Japanese shinbudo is built on spiritual base of medieval Japan as well as on personal beliefs of its founder Morihei Ueshiba. Till today, aikido is considered as a martial path for self-cultivation and self-developing. For aikidokas, it is the adventure of knowing themselves (Wrobel, 2001). Aikido is practiced in dojo. It is more than only the place, the gym, where aikido is practiced. Dojo is also the name for the club, and its members are identified with the dojo. Dojo is a symbolic place pushing practitioner to think about the heritage and meaning of martial art (Donohue, 1990). As Davis (1980) stated, dojo is originally sacred and mystical place. Everyday aikido keiko (training) is part of the concept of shugyo, the method of self-development through physical exercise (renshu). According to Armstrong (1997) some martial arts, koryu in particular, can be called spiritual martial arts. The purpose of this study is to explore spiritual perception of the dojo by aikido practitioners.

\section{Methodology}

Data were collected in members of Czech Aikido Federation, which is organization recognized by Aikido Hombu Dojo, Tokio, headquarters lead by Doshu Moriteru Ueshiba, grandson of aikido founder. 57 aikidokas accepted to participate in this study, 44 male (M) and 13 female (F), age 32.0 \pm 8.3 years. Inclusion criteria were at least 18 years of age, at least 1 year of regular aikido practice, at least $6^{\text {th }}$ kyu. Participants were divided in four groups according to the aikido grade, which correspond with length of practice, to Advanced (A, yudansha, dan holders, $\mathrm{n}=21$ ), Intermediate (I, 2. to 1. Kyu, $n=10)$, Beginners (B, 6. to 3. Kyu, $n=26)$. All participants filled in Spirituality of Movement Activities Questionnaire (Hurych, 2013). Although the 62 items questionnaire widely evaluated four parts of spirituality; in general, general movement, specific activity (martial art of aikido in this case), and environment, for this study we choose the last part. Spirituality of environment consists from 13 items in four dimensions as mysticism, spiritual overlap, inter spirituality and intra spirituality.

For collecting data, Microsoft Excel was used, for further statistical analysis, data were converted to Statistica software. For this presentation, descriptive statistics were used.

\section{Results}

Items in the questionnaire were rated from 1 (lowest spirituality) to 7 (highest spirituality). Average overall spirituality for aikidokas at all levels was $5.71(\mathrm{SD}=1.39)$, while $5.76(\mathrm{SD}=1.42)$ for advanced, $5.67(\mathrm{SD}=1.42)$ for intermediate, and $5.67(\mathrm{SD}=1.35)$ for beginners. In all groups the 
highest average rate was found in spiritual overlap dimension (6.10; $S D=1.26)$, which describes the motivation and will to change, to find meaningful life and ways to achieve it. Spiritual overlap dimension was about the same in all levels (A 6.10; $\mathrm{SD}=1.49$, I 6.08; $\mathrm{SD}=1.02$, B 6.12; $\mathrm{SD}=1.14$ ). Other three dimensions as mysticism (average 5.25; $\mathrm{SD}=1.46$ ), inter spirituality (average 5.72; $\mathrm{SD}=1.29$ ) and intra spirituality (average 5.62; $\mathrm{SD}=1.40$ ) showed similar results at advanced, intermediate, and beginners. The higher average rate $(6.48 ; \mathrm{SD}=0.80$ and $6.46 ; \mathrm{SD}=1.09$ ) was found in questions "I consider dojo friendly" and "I see dojo as a hostile environment". Answers on second question, were inverted, as it was asked as control one.

\section{Discussion and conclusion}

Results show that Aikido practitioners at all levels feel different spiritual dimensions similarly. There are is no evidence, that aikido practice develop environmental spirituality. On other hand, Saotome (1993) describe dojo as a spiritual place, as microcosms, where aikidoka can find his way of life. Also results indicate that motivation for the personal change is rated higher, than other spiritual dimensions. All participants from beginners were adult, so we can expect mature personalities knowing what they are looking for and where. We can see the high rate of spiritual overlap even when comparing results with other movement activities. As Hurych (2013) stated, only recreational cross-country runners had higher relation in this dimension.

Aikido teachers should respect individuality of every aikido student. It is crucial to know their opinion to help them to develop physically, psychologically, or spiritually. Still, spiritual part of development is inextricable from physical exercise.

\section{References}

Green, T. (2001). Martial Arts of the World: An Ecyclopedia, Volume I: A-Q. Santa Barbara: ABC Clio. Wrobel, S. (2001). Aikido for self discovery: blueprint for an enlightened life. St. Paul: Llewellyn publications.

Davis, W. (1980). Dojo: Magic and Exorcism in Modern Japan. Stanford: Stanford University Press.

Donohue, J. J. (1990). Training Halls of the Japanese Martial Rtadition. Anthropos, 85, 55-63

Armstrong, H. B. (1997). The Koryu Bujutsu Experience. In D. Skoss (Ed.), Keiko Shokon: Classical Warrior Traditions of Japan (pp. 19-38). New Jersey: Koryu Books.

Hurych, E. (2013). Spiritualita pohybových aktivit. Brno: Masaryk University.

Saotome, M. (1993). Aikido and the Harmony of Nature. Boston: Shambala.

Key words: Aikido; body and mind; martial arts; combat sports. 